\title{
Intracranial Caseating Granulomas with No Infectious Organism Detected
}

\author{
Amer A. Ghavanini, David G. Munoz.
}

\begin{abstract}
Background: Caseating granuloma is a classic histopathological feature of mycobacterial infections. Occasionally, no infectious organism is demonstrated despite extensive examination of intracranial caseating granulomas. The pathogenesis and optimal management strategy for patients with such intracranial caseating granulomas with no detectable infectious organism (ICGNs) remain unclear. Methods: The study was a retrospective case-series design in a referral hospital setting. Patients with intracranial caseating granulomas in whom no infectious etiology was identified after appropriate investigations were reviewed. Results: Eight patients with ICGN (four females and four males) were identified in an eight-year-period. Average age on presentation was 46 years (range 21-69 years). Cerebrospinal fluid showed lymphocytic pleocytosis, elevated protein and decreased glucose. Neuroimaging showed multiple or single intraparenchymal and meningeal enhancements. Intracranial ICGN were demonstrated on biopsy. Immunomodulation was tried and resulted in improvement in five out of eight patients. In four patients, anti-mycobacterial treatment resulted in no improvement or worsening of clinical or radiological features. Conclusions: The response to therapy of intracranial caseating granulomas where no organism is identified after thorough investigations hints to non-infectious causes, and suggests current dogma regarding the significance of necrosis in granulomatous diseases should be re-evaluated. Our retrospective series suggests that patients may benefit from an early trial of immunomodulation therapy, a hypothesis to be tested in a randomized trial.
\end{abstract}

RÉSUMÉ: Granulomes caséeux intracrâniens sans organisme infectieux. Contexte : Le granulome caséeux est une manifestation histopathologique classique des infections mycobactériennes. Parfois aucun organisme infectieux n'est mis en évidence malgré un examen minutieux des granulomes caséeux intracrâniens (GCIC). La pathogenèse et la stratégie de traitement optimale pour les patients porteurs de tels granulomes demeurent méconnues. Méthodes : Nous avons procédé à une étude rétrospective de cas consécutifs dans le contexte d'un milieu hospitalier spécialisé. Les cas des patients porteurs de granulomes caséeux intracrâniens chez qui aucune étiologie infectieuse n'avait été identifiée après une investigation appropriée, ont été révisés. Résultats : Huit patients, 4 femmes et 4 hommes, porteurs d'un GCIC sans organisme infectieux détectable, ont été identifiés au cours d'une période de 8 ans. L'âge moyen au moment de la consultation initiale était de 46 ans (écart de 21 à 69 ans). L'examen du liquide céphalo-rachidien a montré une pléocytose lymphocytaire, un taux de protéines élevé et un taux de glucose diminué. La neuroimagerie a montré un seul ou plusieurs rehaussements intraparenchymateux et méningés. La présence d'un GCIC a été démontrée par biopsie. Une immunomodulation a été tentée et a produit une amélioration chez 5 des 8 patients. Chez 4 patients, un traitement anti-mycobactérien n'a pas amélioré ou a empiré les manifestations cliniques ou radiologiques. Conclusions : La réponse au traitement des granulomes caséeux intracrâniens dans lesquels aucun organisme pathogène n'est identifié après des examens exhaustifs est compatible avec une cause non infectieuse et remet en question le dogme actuel concernant la signification de la nécrose dans les maladies granulomateuses. L'analyse de notre série rétrospective de cas nous porte à croire que ces patients pourraient bénéficier de l'essai d'un traitement immunomodulateur tôt au cours de la maladie, une hypothèse qui devrait faire l'objet d'un essai randomisé.

Can. J. Neurol. Sci. 2011; 38: 82-87

Granulomas are focal nodular areas of inflammation containing aggregations of epithelioid histiocytes. Caseation, a cheesy appearance on gross examination corresponding to amorphous areas of necrosis on microscopy, is the hallmark of mycobacterial granulomas ${ }^{1}$. However, other infectious and noninfectious systemic pathologies can occasionally manifest with caseating granulomas ${ }^{2-4}$. While immunomodulation therapy is required to treat non-infectious pathologies, immunomodulators carry the risk of infection dissemination ${ }^{5}$. Hence, when facing extracranial caseating granuloma with no detectable infectious organism, some clinicians delay a trial of immunomodulators until after a trial of anti-mycobacterial agents.

Management of intracranial caseating granulomas with no detectable infectious organism (ICGNs) poses an even greater dilemma than when such granuloma is extracranial. In such situations, delaying immunomodulators may result in the progression of a non-infectious etiology and irreversible neurological impairment. There is scarce data on the treatment outcome of this rare condition. Hence, the optimal management

From the Division of Neurology, Faculty of Medicine (AAG), Department of Laboratory Medicine and Pathobiology (DGM), University of Toronto, Toronto, Ontario, Canada.

Received June 14, 2010. Final Revisions Submitted August 19, 2010. Correspondence to: David G. Munoz, Division of Pathology, Department of Laboratory Medicine, St. Michael's Hospital, 30 Bond Street, Toronto, Ontario, M5B 1W8, Canada. 
of ICGNs remains unclear. We reviewed the clinicopathological characteristics and treatment outcomes of ICGNs at our institution. Our observations provided further insight into the management strategy for ICGNs.

\section{METHODS}

We searched the pathology database of St. Michael's Hospital, Toronto for "granuloma" and "brain". We retrieved 42 intracranial granulomas between 2000 and 2008. We reviewed and selected intracranial granulomas with caseating necrosis seen on hematoxylin-phloxine-saffron staining (17 patients). We next excluded eight caseating granulomas in which an infectious agent was identified using rRNA Amplified Mycobacterium tuberculosis Direct Test (AMTD), Ziehl-Neelsen, Auramine Rhodamine, Fite, Silver Methenamine, Periodic Acid-Schiff, Steiner and Gram stains and mycobacterial and routine cultures (seven Mycobacterial and one fungal infections). We excluded one patient for whom tissue AMTD and mycobacterial culture were not available. The remaining eight patients, in whom all the above examinations were negative, are reported here as ICGNs.

The research ethics board of St. Michael's Hospital approved the study.

\section{RESULTS}

We identified eight patients with ICGN (four females and four males). Table 1 summarizes the demographic data and clinical presentation of patients with ICGN. The average age on presentation was 46 years (range 21-69 years; $\mathrm{SEM}=5.8$ years).

The most common presentation was seizures in four patients, followed by confusion in two patients. Somatosensory symptoms were found in one patient (left-sided arm and leg tingling). Other presenting symptoms were bilateral visual loss, double vision and ataxia. While one patient reported malaise and weight loss, none had fever, chills, headache or neck-stiffness. None of the patients reported tuberculosis exposure, although two patients had previously lived in tuberculosis endemic areas. Other tuberculosis risk factors (age, HIV infection, malnutrition, recent measles, alcoholism, underlying malignancy and immunosuppression) were absent in all patients.

Selected laboratory data of patients in our series are summarized in Table 2. None of the patients tested were found to have an elevated angiotensin converting enzyme (ACE) level.
All patients had normal corrected calcium levels (average $=2.3$ $\mathrm{mmol} / \mathrm{L} ; \mathrm{SEM}=0.3 \mathrm{mmol} / \mathrm{L}$ ). Erythrocyte sedimentation rate (ESR) was measured in only four patients (range 2-88 mm/hr), and was elevated in three. Antinuclear antibody (ANA) was negative in all six patients in whom it was measured. In addition to the laboratory data summarized in table 2, there were negative Treponema pallidum IgG and IgM, VDRL, toxoplasma IgG, Lyme, cytomegalovirus serology, extractable nuclear antigens, anti-neutrophil cytoplasmic antibodies, rheumatoid factor and complements in four tested patients.

Cerebrospinal fluid (CSF) analysis was available in four patients (Table 2). One patient had three lumbar punctures and two other patients had two lumbar punctures. While three patients had elevated CSF leukocytes ranging from 23 to 322 white blood cells (WBC) $/ \mathrm{mm}^{3}$, one patient had three $\mathrm{WBC} / \mathrm{mm}^{3}$. In all cases, there was lymphocytic predominance. All CSF samples had elevated protein levels ranging from 0.75 to 2.94 $\mathrm{g} / \mathrm{L}$. Cerebrospinal fluid glucose was decreased in all but one sample (range 1-3.7 mmol/L). All CSF samples were negative for Ziehl-Neelsen stain, AMTD, mycobacterial fluorescent smear and myco-bacterial culture. Additionally, all CSF samples had negative Polymerase chain reaction (PCR) for herpes simplex virus group and West-Nile virus, gram stain, bacterial and fungal cultures, cryptococcal antigen, cytology and VDRL.

Neuroimaging findings are summarized in Table 3. Contrast enhanced magnetic resonance imaging (MRI) of brain was available in five patients. In four patients, MRI of brain showed multiple supra-tentorial intraparenchymaal T2/FLAIR hyperintense lesions. These lesions showed homogeneous gadolinium enhancement. Meningeal gadolinium enhancement was observed in all of these patients (Figure 1). In three of these patients, similar lesions were also found in the infra-tentorial areas of the brain. One patient had a single supratentorial T2/FLAIR hyper-intense lesion with homogenous gadolinium enhancement. This patient did not have meningeal enhancement. Contrast enhanced computed tomogram (CT) of brain was available in three patients, who didn't have an MRI of brain. Two of these patients had single ring-enhancing supra-tentorial intraparenchymal lesions and the other had a single irregularlyenhancing supra-tentorial intraparenchymal lesion. Hydrocephalus was seen in two patients, one of whom had a ringenhancing lesion. Calcification of the lesion was seen in two out of the three CT scans of brain. Magnetic resonance imaging of

Table 1: Demographic data and clinical presentation of patients with ICGN

\begin{tabular}{lllll}
\hline Patient & Age (years) & Sex & Presentation & Constitutional Symptoms \\
\hline 1 & 69 & M & Ataxia & None \\
2 & 53 & F & Bilateral Visual Impairment & None \\
3 & 54 & F & Diplopia & Malaise, weight loss \\
4 & 21 & M & Seizure & None \\
5 & 29 & M & Seizure & None \\
6 & 41 & F & Seizure, Tingling of left arm and leg & None \\
7 & 34 & F & Seizure, Confusion & None \\
8 & 67 & M & Confusion & None \\
\hline
\end{tabular}


Table 2: Selected laboratory data of patients with ICGN.

\begin{tabular}{llllllll}
\hline Patient & $\begin{array}{l}\text { ACE } \\
\text { U/L } \\
(9-63)\end{array}$ & $\begin{array}{l}\text { Serum } \\
\text { Calcium } \\
\text { mol/L } \\
(2.1-2.6)\end{array}$ & $\begin{array}{l}\text { ESR } \\
\mathrm{mm} / \mathrm{h} \\
(0-20)\end{array}$ & ANA & $\begin{array}{l}\text { CSF } \\
\text { WBC/mm } / \mathrm{mm}^{3}\end{array}$ & $\begin{array}{l}\text { CSF } \\
\text { Protein } \\
\text { g/L } \\
(<0.45)\end{array}$ & $\begin{array}{l}\text { CSF } \\
\text { Glucose } \\
\mathrm{mmol} / \mathrm{L}\end{array}$ \\
\hline 1 & 16 & 2.3 & 2,4 & Neg. & 164,93 & $2.94,2.39$ & $1,1.3$ \\
2 & 10 & 2.1 & NA & Neg. & $253,322,237$ & $1.06,1.22,1$ & $1.9,2,2$ \\
3 & 11 & 2.4 & 4,41 & Neg. & 23,48 & $0.75,1.09$ & $3.6,3.7$ \\
4 & NA & 2.2 & NA & NA & NA & NA & NA \\
5 & NA & 2.3 & NA & NA & NA & NA & NA \\
6 & 35 & 2.3 & 28 & Neg. & NA & NA & NA \\
7 & 23 & 2.4 & 30,88 & Neg. & 3 & 1.68 & 2.6 \\
8 & 6,16 & 2.3 & NA & Neg. & NA & NA & NA \\
\hline
\end{tabular}

NA, Not Available; Neg., Negative; Numbers in brackets represent reference values

spine was available in five patients. While three patients had multiple intradural patchy-nodular enhancing lesions in MRI of spine, two patients had normal MRI of spine. Overall, a heterogeneous radiological pattern with both intraparenchymal and meningeal enhancements was observed.

Chest X-ray and CT scan was available in all patients. Hilar lymph nodes were only detected on two chest CT scans, one of which was biopsied. Whole body gallium scans, performed in five patients, were negative.

Tissues examined included brain parenchyma (five patients), meninges (two patients) or both (one patient). One patient had hilar lymph node biopsy in addition to brain and meninges. Focal areas of granulomatous inflammation containing aggregations of histiocytes with caseating necrosis were seen on all biopsies (Figure 2), including one hilar lymph node biopsy. Immunocytochemical analysis of the cellular infiltrate revealed predominately CD68 positive macrophages and scattered CD3 positive T-lymphocytes and CD20 positive B- lymphocytes. No microorganism was identified in extensive tissue examination, as described in methods.

Clinical and radiological responses to treatment are detailed in Table 4. None of the patients had received anti-microbial

Table 3: Neuroimaging findings in patients with ICGN

\begin{tabular}{|c|c|c|c|}
\hline Patient & MRI Brain & CT Brain & MRI Spine \\
\hline 1 & $\begin{array}{l}\text { Multiple FLAIR positive homogeneously } \\
\text { enhancing meningeal and intraparenchymal supra- } \\
\text { and infra-tentorial lesions }\end{array}$ & Not available & $\begin{array}{l}\text { Extensive patchy- } \\
\text { nodular } \\
\text { enhancements }\end{array}$ \\
\hline 2 & $\begin{array}{l}\text { Multiple FLAIR positive homogeneously } \\
\text { enhancing meningeal and intraparenchymal supra- } \\
\text { and infra-tentorial lesions }\end{array}$ & Not available & $\begin{array}{l}\text { Extensive patchy- } \\
\text { nodular } \\
\text { enhancements }\end{array}$ \\
\hline 3 & $\begin{array}{l}\text { Single homogenously enhancing supratentorial } \\
\text { dural lesion }\end{array}$ & Not available & Normal \\
\hline 4 & Not available & $\begin{array}{l}\text { Single ring enhancing } \\
\text { intraparenchymal lesion with } \\
\text { calcification }\end{array}$ & Not available \\
\hline 5 & Not available & $\begin{array}{l}\text { Single irregularly enhancing } \\
\text { intraparenchymal lesion with } \\
\text { calcification }\end{array}$ & Not available \\
\hline 6 & $\begin{array}{l}\text { Multiple FLAIR positive homogeneously } \\
\text { enhancing meningeal and intraparenchymal supra- } \\
\text { tentorial lesions }\end{array}$ & Not available & Normal \\
\hline 7 & $\begin{array}{l}\text { Multiple FLAIR positive homogeneously } \\
\text { enhancing meningeal and intraparenchymal supra- } \\
\text { and infra-tentorial lesions, mild hydrocephalus ex } \\
\text { vacuo }\end{array}$ & Not available & $\begin{array}{l}\text { Extensive patchy- } \\
\text { nodular } \\
\text { enhancements }\end{array}$ \\
\hline 8 & Not available & $\begin{array}{l}\text { Single ring enhancing } \\
\text { intraparenchymal lesion with } \\
\text { hydrocephalus }\end{array}$ & Not available \\
\hline
\end{tabular}




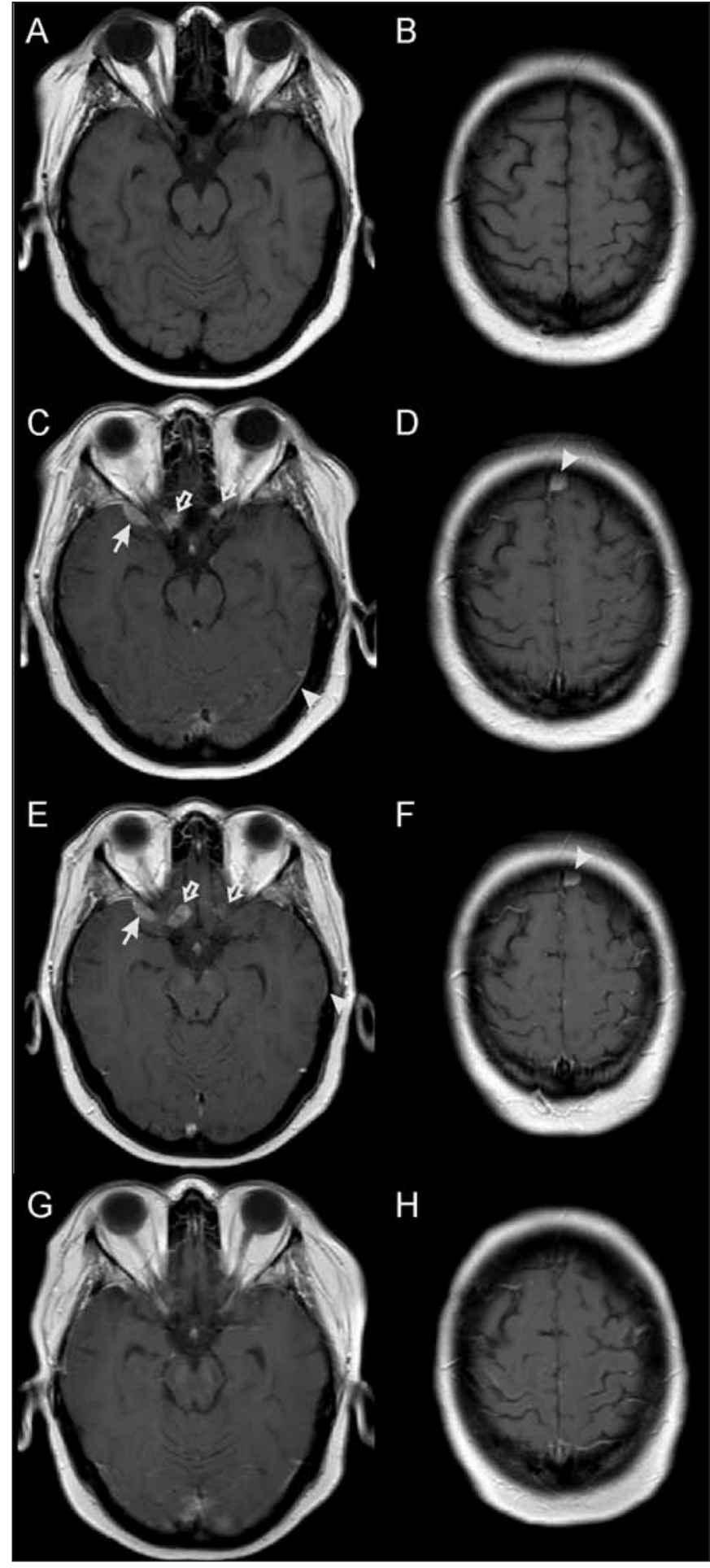

Figure 1: MRI of brain in a patient with ICGN. Multiple supratentorial intra- (arrow) and extra-axial (open arrows) as well as meningeal (arrowhead) enhancements are seen $(C \& D$; compare to non-enhanced images $A \& B)$. Lesions slightly increased in size after tapering an initial short course of steroids while on anti-mycobacterial treatment $(E \& F)$ and completely resolved on immunomodulation therapy alone $(G \& H)$. therapy prior to biopsy. The attending physicians initiated immunomodulation therapy without a trial of anti-mycobacterial therapy in Patients 1, 6 and 7 because of their low clinical suspicion for tuberculosis and high clinical suspicion for sarcoidosis. In Patients 2 and 3, immunomodulation therapy was started one to two months after an initial anti-mycobacterial therapy because of clinical and/or radiological worsening. Both of these patients developed bilateral leg weakness during this initial anti-mycobacterial therapy necessitating wheelchair for ambulation. Patients 5 and 8 showed neither improvement nor worsening on anti-mycobacterial therapy over 26 and 48 months of follow-up. Given no clinical progression, immuno-

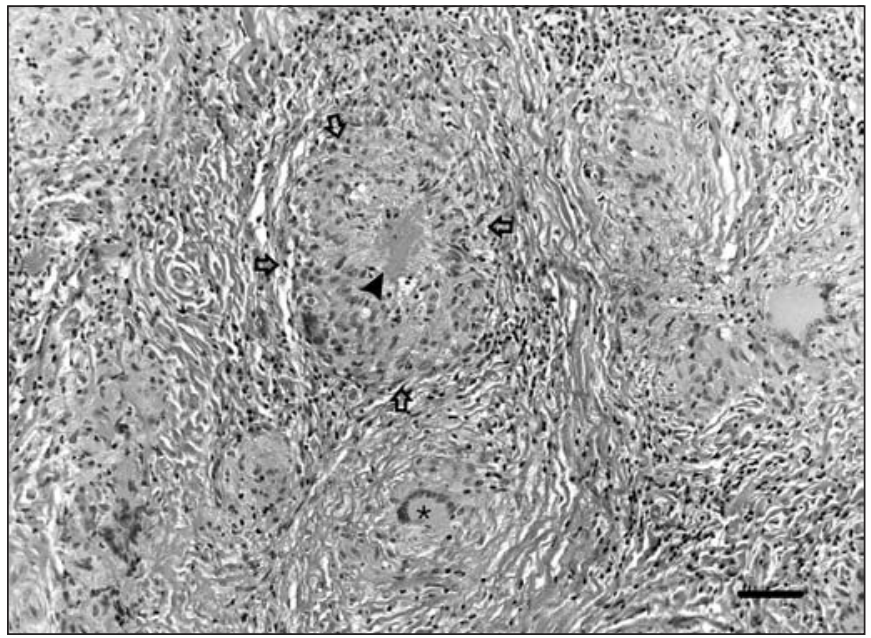

Figure 2: Multiple granulomas with caseating necrosis. Hematoxylin Phloxine Saffron (HPS) staining of leptomeningeal biopsy. Arrows outline a granuloma and arrowhead indicates central caseating necrosis. Asterisk indicates a multinucleated giant cell. Scale bars represent 50 $\mu m$.

modulation therapy was not tried in these patients. Overall, five out of seven treated patients clearly responded to immunomodulators (Patients 1, 2, 3,6 and 7). This included two patients with a delay of one to two months in initiation of immunomodulation therapy due to an unsuccessful trial of antimycobacterial therapy (Patients 2 and 3), as well as three patients with early treatment with immunomodulation therapy in the other three patients (Patients 1,6 and 7). Prednisone alone was used in two patients and a combination of prednisone and azathioprine in three patients. Prednisone was started at $1 \mathrm{mg} / \mathrm{kg}$ with slow taper over six months. One patient relapsed while prednisone was tapered. Prednisone had to be restarted. Azothioprine was started at $50 \mathrm{mg}$ per day and titrated up with final dose of 100 to $150 \mathrm{mg}$ per day. Radiologically, immunomodulation therapy resulted in complete resolution of the lesions in three (Patients 2, 6 and 7) and decrease in lesion size in another (Patient 1). Clinically, three patients had improved 
Table 4: Response of patients with ICGN to treatment.

\begin{tabular}{|c|c|c|c|}
\hline Patient & Anti-Mycobacterial Therapy* & Immunomodulation Therapy & Follow-Up \\
\hline 1 & Not tried & $\begin{array}{l}\text { Clinical and radiological improvement on } \\
\text { prednisone }\end{array}$ & 6 months \\
\hline 2 & $\begin{array}{l}\text { Clinical and radiological worsening with } \\
\text { development of new lesions while on anti- } \\
\text { mycobacterial therapy and tapering of } \\
\text { prednisone }\end{array}$ & $\begin{array}{l}\text { Clinical improvement and complete } \\
\text { radiological resolution on prednisone } \\
\text { Recurrence upon tapering and improvement } \\
\text { upon restarting prednisone and azathioprine }\end{array}$ & 7 months \\
\hline 3 & $\begin{array}{l}\text { Non-continuous trials were discontinued due } \\
\text { to lack of clinical improvement and clinical } \\
\text { worsening upon tapering of prednisone }\end{array}$ & $\begin{array}{l}\text { Clinical improvement on prednisone } \\
\text { Recurrence upon tapering and improvement } \\
\text { upon restarting prednisone }\end{array}$ & 6 months \\
\hline 4 & $\begin{array}{l}\text { Returned to home country before any } \\
\text { treatment }\end{array}$ & $\begin{array}{l}\text { Returned to home country before any } \\
\text { treatment }\end{array}$ & Unavailable \\
\hline 5 & $\begin{array}{l}\text { Full course with neither improvement nor } \\
\text { worsening }\end{array}$ & Not tried & 26 months \\
\hline 6 & Not tried & $\begin{array}{l}\text { Clinical improvement and complete } \\
\text { radiological resolution on prednisone and } \\
\text { azathioprine }\end{array}$ & 32 months \\
\hline 7 & Not tried & $\begin{array}{l}\text { Clinical improvement and complete } \\
\text { radiological resolution on prednisone and } \\
\text { azathioprine. Recurrence upon tapering and } \\
\text { improvement upon restarting prednisone and } \\
\text { azathioprine }\end{array}$ & 7 years \\
\hline 8 & $\begin{array}{l}\text { No improvement with anti-mycobacterial } \\
\text { therapy. A ventriculoperitoneal shunt prior } \\
\text { to anti-mycobacterial therapy had resulted in } \\
\text { slight initial improvement }\end{array}$ & Not tried & 48 months \\
\hline
\end{tabular}

*Isoniazid, Rifampin, Pyrazinamide, and Vitamin B6 in all cases

ambulation and went from using a wheelchair to ambulating independently (Patient 1, improved ataxia) and to ambulating with a walker (Patients 2 and 3, improved leg weakness). One patient, who also had complete radiological resolution, remained seizure free 32 months after presentation (Patient 6). One patient was seizure-free and had improvement in her cognitive impairment to the extent that she became employed (Patient 7). Recurrence was noted after the tapering of immunomodulation therapy in three of the five patients (Patients 2, 3 and 7) and necessitated reinstating immunomodulation therapy. In two patients who did not receive immunomodulators, there was no clear response to anti-mycobacterial therapy. Figure 1 shows complete radiological resolution on immunomodulators, after an initial worsening on anti-mycobacterial therapy (Patient 2).

\section{DISCUSSION}

This series describes an uncommon clinical occurrence, designated as ICGN, defined by negative infectious investigations in the presence of intracranial caseating granulomas. The neurological manifestations were as expected, but the absence of constitutional symptoms was noteworthy, especially in view of the elevated cells and protein and decreased glucose in CSF. The enhancing intrapenchymal lesions were often, but not always, accompanied by meningeal enhancement. Most remarkably, immunomodulation therapy was required in the majority of the patients. In contrast, there was no clear benefit of anti-mycobacterial therapy. These observations suggest an earlier trial of immunomodulation therapy may be beneficial in the management of ICGNs.

Central nervous system (CNS) involvement occurs in a small fraction of tuberculosis patients ${ }^{6}$. This condition carries a high mortality necessitating prompt treatment ${ }^{6}$. Detection of mycobacteria in CSF by Ziehl-Neelsen staining or mycobacterial culture confers a variable sensitivity of $20 \%$ to $90 \%$ (reviewed in Rock et $\mathrm{al}^{6}$. The sensitivity of staining or culture for detection of mycobacteria has not been studied separately in CNS tissue. In a study that included CNS tissue amongst other tissues, staining and culture detected mycobacteria with $42 \%$ and $55 \%$ sensitivities, respectively ${ }^{7}$. Polymerase chain reaction-based CSF assays such as AMTD have higher sensitivities ${ }^{6}$. In tissue, PCR-based assays confer a sensitivity of 70-80\% with negative predictive value of $88-97 \%^{7,8}$. The data on the negative predictive value of a combination of the above tests is scarce. In one study comparing these tests among 20 patients with clinically confirmed tuberculous pericarditis, all tissues were positive for at least one of Ziehl-Neelsen examination, mycobacterial culture or $\mathrm{PCR}^{9}$. In another study examining 115 tissue samples from various organs showing granuloma and negative Ziehl-Neelsen examination, 13 samples were found to be also negative for mycobacterial culture and $\mathrm{PCR}^{10}$. However, unlike the former study, the clinical diagnosis of tuberculosis in these patients did not include response to treatment on followup. While false negative Ziehl Neelsen, mycobacterial culture and PCR examinations is a possibility, response to treatment in 
our patients was not compatible with a diagnosis of mycobacterial infection. Hence, the combination of the above tests was clinically more meaningful than the observation of caseating granulomas in histopathologic examinations.

The nature of the caseating granulomas in our patients remains unclear. An atypical presentation of sarcoidosis is the main diagnostic consideration. Granulomata of sarcoidosis are classically non-caseating. Any presence of caseation within sarcoid granulomas necessitates a re-examination of the tissue to ensure an infectious etiology has not been overlooked ${ }^{11}$. Two of our patients had hilar lymphadenopathy, which supported a diagnosis of sarcoidosis. All our tested patients including those with hilar lymphadenopathy had normal ACE levels. However, the sensitivity of serum ACE in sarcoidosis is only $50-60 \%{ }^{12}$. ANCA-associated vasculitides, i.e. Wegener's granulomatosis, microscopic polyangiitis, and Churg-Strauss syndrome, are another diagnostic consideration. Among these, Wegener's granulomatosis can show both granulomas and necrosis, although necrosis is limited to the vessel walls and does not produce a picture of caseating granulomas ${ }^{13}$. ANCA was negative in all our tested patients. Granulomas can be seen in other vasculitides such as giant cell arteritis and Takayasu disease, but are typically non-necrotizing ${ }^{13}$. Given the uncertainty regarding the etiology underlying the observed caseating granulomas, we grouped all the patients under ICGN.

We find the designation of ICGN clinically useful, despite lacking etiological significance. The majority of our patients (five out of seven) required immunomodulation therapy. Three patients had complete radiological resolution of their lesions on prednisone and azathioprine. This suggests that the clinical improvement observed in these patients resulted from a response of the disease process to the treatment rather than mere reduction in edema. Two of these patients had worsening on antimycobacterial treatment. Hence, when a rigorous investigation that includes tissue examination fails to identify an infectious cause in patients with intracranial caseating granulomas, a designation of ICGN and an early trial of immunomodulation therapy may be beneficial.

\section{Conclusions}

Our study was limited by the retrospective quality of data. Ideally, a double-blind randomized clinical trial is needed to establish the optimal management of ICGNs. However, given the scarcity of ICGNs, a retrospective case series is the only feasible design to answer the questions approached hereby.

\section{REFERENCES}

1. Jarzembowski JA, Young MB. Nontuberculous mycobacterial infections. Arch Pathol Lab Med. 2008;132(8):1333-41.

2. Torrelo A, Mediero IG, Zambrano A. Caseating cutaneous granulomas in a child with common variable immunodeficiency. Pediatr Dermatol. 1995;12(2):170-3.

3. Fleming MG, Gewurz AT, Pearson RW. Caseating cutaneous granulomas in a patient with X-linked infantile hypogammaglobulinemia. J Am Acad Dermatol. 1991;24(4):629-33.

4. Johnson LN, Iseri O, Knodell RG. Caseating hepatic granulomas in Hodgkin's lymphoma. Gastroenterology. 1990;99(6):1837-40.

5. Muñoz P, Rodríguez C, Bouza E. Mycobacterium tuberculosis infection in recipients of solid organ transplants. Clin Infect Dis. 2005;40(4):581-7.

6. Rock RB, Olin M, Baker CA, Molitor TW, Peterson PK. Central nervous system tuberculosis: pathogenesis and clinical aspects. Clin Microbiol Rev. 2008;21(2):243-61

7. Salian NV, Rish JA, Eisenach KD, Cave MD, Bates JH. Polymerase chain reaction to detect Mycobacterium tuberculosis in histologic specimens. Am J Respir Crit Care Med. 1998;158(4): 1150-5.

8. Chawla K, Gupta S, Mukhopadhyay C, Rao PS, Bhat SS. PCR for M. tuberculosis in tissue samples. J Infect Dev Ctries. 2009;3(2): 83-7.

9. Cegielski JP, Devlin BH, Morris AJ, et al. Comparison of PCR, culture, and histopathology for diagnosis of tuberculous pericarditis. J Clin Microbiol. 1997;35(12):3254-7.

10. Li JY, Lo ST, Ng CS. Molecular detection of Mycobacterium tuberculosis in tissues showing granulomatous inflammation without demonstrable acid-fast bacilli. Diagn Mol Pathol. 2000;9(2):67-74

11. Cavazza A, Harari S, Caminati A, et al. The histology of pulmonary sarcoidosis: a review with particular emphasis on unusual and underrecognized features. Int J Surg Pathol. 2009;17(3):219-30.

12. Parrish S, Turner JF. Diagnosis of sarcoidosis. Dis Mon. 2009;55 (11):693-703.

13. Lamprecht P, Wieczorek S, Epplen JT, Ambrosch P, Kallenberg CG. Granuloma formation in ANCA-associated vasculitides. APMIS Suppl. 2009;127:32-6. 